S sciendo

\title{
Time Travel and the Open Future
}

\author{
Kristie Miller \\ University of Queensland
}

Disputatio Vol. 1, No. 19

November 2005

DOI: $10.2478 /$ disp-2005-0009

ISSN: 0873-626X 


\title{
Time travel and the open future
}

\author{
Kristie Miller \\ University of Queensland
}

\begin{abstract}
I argue that the thesis that time travel is logically possible, is inconsistent with the necessary truth of any of the usual 'open future-objective present' models of the universe. It has been relatively uncontroversial until recently to hold that presentism is inconsistent with the possibility of time travel. I argue that recent arguments to the contrary do not show that presentism is consistent with time travel. Moreover, the necessary truth of other open future-objective present models which we might, prima facie, have supposed to be more amenable to the possibility of time travel, turn out also to be inconsistent with this possibility.
\end{abstract}

Let us say that a particular model of the universe is an 'open futureobjective present' model just if (i) according to the model there exist intrinsic properties of pastness, presentness and futurity such that for any given time $t$, there is a single moment that is the objective present, and, for any ontologically real moment that is other than the objective present, that moment is either in the objective past or the objective future and (ii) given that time $t$ is the objective present, it is genuinely indeterminate what events will occur at temporal locations that are in the objective future.

There are basically three different models that are consistent with the open future-objective present view of the universe. Two of these models are consistent with, but do not entail the truth of the open future-objective present model, while one is not only consistent with that model, but also entails it. Perhaps the most obvious of these models is presentism. According to presentists, only the present moment is ontologically real, and past and future locations are ontologically unreal. So presentism entails that there exists an objective present - the only ontologically real temporal location. It need not entail, however, that there exists an open future. After all, presentists do not hold that there exists an open past, despite the fact that past temporal locations are not, by their lights, ontologically real. The 'higher-order property' apparatus that presentists appeal to when

Disputatio, Vol. I, No. 19, November 2005 
dealing with past events could, then, equally be applied to future events: then the future would be closed, despite the fact that future temporal locations are ontologically unreal. Though this position is consistent with presentism, I take it that in general presentists do hold that the past is closed and the future open. Henceforth then, when I talk of presentism I mean to refer to the usual brand of open futureobjective present presentism.

There are two other possible models of an open future-objective present universe. The first of these is the 'growing universe' model as proposed by Tooley 1997 and Forrest forthcoming. On this model there exists a single four-dimensional trunk that contains all of the temporal locations in the objective past, and at the very 'edge' of that trunk is the objective present which peers into nothingness, since no future temporal locations are ontologically real. Unlike presentism them, the growing universe model holds that all past temporal locations are ontologically real, and thus that the past not only is, but must be, closed. But like presentism, it holds that there is an objective present, and that all objectively future temporal locations are ontologically unreal. Like presentism then, the growing universe model is likely consistent with a closed future, since it is possible that one might adopt this model and then adopt the sort of higher-order property apparatus conceived of by the presentist, to then analyse a closed but non-existent future. Once again, however, I take it that those who embrace the growing universe model consider it to be a virtue of the model that it provides the basis for a genuine difference between past and future events, insofar as the past is closed and the future open, the past real and the future unreal. Henceforth then, by the growing universe model I intend to refer to the usual understanding of this model that is both an objective present and an open future model.

Finally we come to the third model: the branching universe model as proposed by McCall 1994. Like the growing universe model, on the branching universe model there exists a single four-dimensional trunk that contains all of the temporal locations in the objective past. The objective present lies at the end of that trunk peering into an array of non-actual but ontologically real future branches. On this model then, not only must the past be closed, but the future must be open: each of the non-actual future branches represents one possible way that things could be, given the way they are in the objective present. This model then, entails that there is both an objective present and an open future. 
The key difference between the growing universe and the branching universe then, is that all possible objectively future temporal locations are ontologically real on the branching universe model, and are unreal on the growing universe model. Since both are committed to the existence of an objective present, and thus to the existence of intrinsic properties of pastness, presentness and futurity, both sit squarely within the A-series tradition. Even in the case of the branching universe model, there is no truly tenseless way to describe the relations between events, because when future branches 'drop off' as a result of failing to become actual, there are events at temporal locations that go from 'pseudo-tenselessly' existing — existing relative to the total snapshot of the universe when time $t$ is the present - to failing to 'pseudo tenselessly' exist — not existing relative to some other total snapshot of the universe when time $t *$ is the present.

With these three open future-objective present models in mind then, let us consider the following set of assumptions:

(1) Necessarily, P is a genuine time traveller only if all of P's temporal stages are united by some causal relation. ${ }^{1}$

(2) It is not logically possible to change the past.

(3) It is not logically possible to travel from a non-existent location to an existent location.

(4) Time travel is logically possible.

(5) Necessarily, our world has an objective present and an open future.

In what follows I will first argue that assumptions (1)-(3) are plausible. I will then show that if we accept these plausible assumptions, we find that the combination of (1)-(3) is inconsistent with the truth of both (4) and (5). If (1)-(3) are true, then either (4) is false and time travel is not logically possible, or (5) is false and it is not the case that necessarily, our world has an objective present and an open future.

So why think that assumptions (1)-(3) are plausible? Well assumption (1) merely rules out as genuine time travel, cases in which some object $\mathrm{O}$ disappears at a time $\mathrm{t}$, and at some earlier time $\mathrm{t}-$, a qualitative duplicate of $\mathrm{O}$ at $\mathrm{t}$ suddenly appears, but where there is no causal relation between $\mathrm{O}$ at $\mathrm{t}$ and the duplicate, at $\mathrm{t}-$, of $\mathrm{O}$ at $\mathrm{t}$. We might

\footnotetext{
${ }^{1}$ Or for those who are not four-dimensionalists, $\mathrm{P}$ is a genuine time traveller only if for every times $\mathrm{t}$ and $\mathrm{t} *$ at which $\mathrm{P}$ exists, there is some causal relation that holds between $\mathrm{P}$ at $\mathrm{t}$ and $\mathrm{P}$ at $\mathrm{t}^{*}$.
} 
want to call this pseudo time travel, but most would agree that it is not genuine time travel. After all, most of us think that the kinds of objects we find around us only persist if the right sorts of causal relations hold between their object-stages or, for three-dimensionalists, between the object considered at one time, and considered at another time. But then the object that exists at $\mathrm{t}$ - is not $\mathrm{O}$ at all, and consequently $\mathrm{O}$ has not travelled in time.

Assumption (2) is the almost universally accepted claim that it is logically impossible to change the past, and I will not defend that claim here. $^{2}$

Assumption (3) is the claim that it is not possible to travel from a non-existent location to an existent location. This is the inverse of the 'no destination' objection that has been levelled against the possibility of time travel given the truth of presentism. According to Grey 1999, for instance, presentists cannot travel backwards in time, since there exist no past locations to which to travel. Until recently it seemed to be accepted wisdom that presentism is inconsistent with the possibility of time travel. After all, if there is no past to travel to, how can we travel there? And on those grounds, one might, prima facie, think that the growing and branching universe models ought to fare better when it comes to time travel: after all, according to each of these models there is an ontologically real past to which one could travel. In what follows I argue that we were right all along to hold that presentism is inconsistent with the possibility of time travel, and furthermore, that so too are the other two models of an open future and objective present.

Dowe 2000 disagrees, however. He argues that if Grey's 1999 argument were sound, it would imply that presentists cannot 'travel' into the future either, since there exist no future locations to which to travel. All that is required, argues Dowe, is that a destination exists once one reaches it, not that it exists prior to one leaving on one's journey. If that is the case, then presentists ought to be able to travel to the past. Of course, in some sense the presentist can never travel to the past. Rather, what is the case is that it is now true that some current individual did exist in the past, and that individual's existence in the past is caused by her existence in the present.

\footnotetext{
${ }^{2}$ Though recently Goddu (2003) has argued that it is possible to change the past, it is not clear that his account is not ultimately one in which we have a branching universe, and the time traveller does not change the past, but rather, somehow 'switches' branches.
} 
There is another way to think about the presentist case, and that is a way that will become important when we turn our attention to the growing and branching universe cases. We tend to think of presentist time travel in terms of a traveller leaving from an existent location call it $\mathrm{t}+$, and heading towards a non-existent location in the past, call it $t$. Since it is not possible to change the past, however, it follows that if one can travel to some past temporal location $\mathrm{t}$, it will be true at all times subsequent to $t$, that one existed at $t$. And it will be true at $t$, that one exists at $t$. What it means to say that one can travel to the past (t) so long as the past is there when one gets there, is that one can make it the case that when $t$ is the present, one exists at $t$. If one does not exist at $t$ when $t$ is the present, then it is not the case that one did exist at $\mathrm{t}$ when $\mathrm{t}$ is the past, and thus not the case that one has travelled to $t$.

Yet if the time traveller exists at $t$ when $t$ is the present, it looks as though we have to say that the traveller has travelled from a non-existent location (the future $\mathrm{t}+$ ). And while travelling to a non-existent location from an existent one might sound plausible, travelling from a non-existent location to an existent one sounds like a tricky task. To that latter problem one might say the following: it is no more problematic to travel from a destination which is, from the perspective of the time of arrival, non-existent, than it is to travel to a destination which is, from the perspective of the departure, non-existent. All that matters in both cases is that the each end of the journey exists when one is at that end. Thus just as in the previous case all that is required is that the destination exist at the time of arrival, in this case all that is required is that the departure location exist at the time of departure, not that it exist at the time of arrival.

Perhaps so. But there are two things to notice here. The first is that there is something very odd about the picture of cause and effect given this scenario. At $t$, the time traveller exists. We can imagine him there, flesh and blood. But the cause of that time traveller existing at $t$ - one of the things that makes him a genuine time traveller — does not exist. It is not simply that the cause is in the future and does not exist now, rather, the cause simply does not exist at all. What is true is that the time traveller's existing at $\mathrm{t}+$ (when $\mathrm{t}+$ is the present) is the truth maker for the claim that the time traveller did exist at $\mathrm{t}$ : for it is the higher-order properties of the time traveller at $\mathrm{t}+$, that renders true the statement that she did exist at $t$. Yet it remains unclear in exactly what sense the time traveller's existence at $\mathrm{t}+$, causes her 
existence at $\mathrm{t}$, given that she exists at $\mathrm{t}$ even when the so-called cause of that existence fails to itself exist. So it seems that the causal work of the future states at $\mathrm{t}+$ is shadowy at best.

Moreover, on the model we are considering we have an open future. So it is supposed to be indeterminate what events occur in the future. While the higher-order properties of the things that exist in the present are supposed to determine what statements about the past are true, that is, are supposed to determine what was the case, they are not supposed to determine what will be the case. So at $t$, it must be indeterminate whether the time traveller will exist at $t+$, and whether she will decide to travel back in time. So we cannot even say that it is the case that if it were not for the fact that the traveller will exist at $\mathrm{t}+$ and travel back in time, he would not exist in the present. For while we know that the 'traveller' exists at $t$, there is no guarantee that he will exist at $\mathrm{t}+$ and travel back in time. Then it must be indeterminate whether the future state at $\mathrm{t}+$, is in fact the cause of the time traveller at $t$. But it is hard to make sense of the idea that it can be indeterminate whether $\mathrm{x}$ is the cause of $\mathrm{y}$ or not. This seems to render the causal work of the future states at $\mathrm{t}+$ even more shadowy, and what is more, suggests that it is indeterminate whether the individual who exists at $t$, is a genuine time traveller or not.

So what should we think about the presentist and time travel? Clearly those who find the original form of the 'no destination' argument compelling will equally find the new version so. But even those who are not moved by the original argument might well find this new argument compelling: for it seems genuinely puzzling how it can be that, even given that we accept that it is possible to travel from what is now a non-existent location to what is now an existent location, it can be possible for a future non-existent state to cause a current event, particularly given that the nature of the future is indeterminate. It seems to me, therefore, that the presentist has not provided a plausible account of how there can be time travel. And if that is so then, I will argue, it follows that neither of the other two models of the open future-objective present are consistent with time travel either.

So let us put aside for a moment the case of presentism, and turn to the other two models. Let us first consider the growing universe model. Then let us read (5) as (5a):

(5a) Necessarily, our world is a growing universe. 
It seems as though the growing universe model might be immune to some of the problems the presentist faces when it comes to time travel. For the growing universe seems to avoid the objection that I cannot travel back in time since there is no location to which to travel: for the growing universe model holds that all past temporal locations are ontologically real. So there seems no reason to suppose I cannot travel to them. If $\mathrm{t}_{5}$ is the objective present, then I ought to be able to travel to all temporal locations that are in the objective past relative to $t_{5}$. But is that so?

Suppose that $t_{5}$ is the objective present, and at $t_{5}$ Fred travels back in time to $t_{1}$. Given (2), it is not possible for Fred to change the past. So if Fred exists at $t_{1}$ when $t_{1}$ is the objective past, then Fred must exist at $t_{1}$ when $t_{1}$ is the objective present. When $t_{1}$ is the objective present, $t_{5}$ does not exist. So it is not possible for any time traveller to have travelled from $t_{5}$ to $t_{1}$. Therefore time travelling Fred cannot exist at $t_{1}$ when $t_{1}$ is the objective present, and hence he cannot exist at $t_{1}$ when $t_{1}$ is the objective past either. Or, to put it another way, if Fred does exist at $t_{1}$ then he is not a time traveller, since when $t_{1}$ is the objective present, his $t_{1}$ person-stage is not causally connected to any personstage that exists in the future, since such a stage does not exist.

All of this, of course, is just to say that the growing universe model is faced with exactly the same problem as the presentist model: it requires that present states be caused by non-existent indeterminate future states.

Not let us consider the final way (5) could be true: if necessarily our world were a branching universe. Then let us read (5) as (5b):

(5b) Necessarily, our world is a branching universe.

In the branching model, future branches represent all of the various nomologically possible ways things could be, given the way they are in the objective present. Though these possibilities are 'nonactual', they are located within our universe and are ontologically real. All future branches that do not become actual, that is, part of the single trunk that represents the objective present and past, 'drop off' and cease to exist.

Now again, suppose that $t_{5}$ is the objective present, and a time traveller travels back to $t_{1}$. Then, by (2), as before it follows that when $t_{1}$ is the objective present, the time traveller exists at $t_{1}$. When $t_{1}$ is the objective present, $t_{5}$ is the objective future. Unlike in the case of 
presentism and the growing universe model however, future temporal locations are ontologically real. So, we might think, there is no problem in holding that the time traveller's location at future times causes his existence at $\mathrm{t}_{1}$. For the traveller does exist at $\mathrm{t}_{5}$, and therefore has the appropriate causal connections with himself at $\mathrm{t}_{1}$.

But consider the following scenario. Consider the existence of just two possible future branches. On one branch Fred exists. Fred comes into existence at $t_{2}$, and continues to exist through $t_{5}$. On the other branch there exists Mary, who also comes into existence at $t_{2}$, and continues to exist through $t_{5}$. So when $t_{1}$ is the objective present, neither Mary nor Fred exist on the trunk of the four-dimensional tree. Thus if Fred or Mary's branches fail to be actualised and thus drop off the tree, there will be no record of either having existed neither will exist at any point on the trunk. Unless of course, they travel in time.

Let us suppose that it is Fred's branch that will become actual, and thus Mary's that will drop off. If the future is genuinely indeterminate, then at $\mathrm{t}_{1}$ either Fred or Mary could become actual, and since both are equally ontologically real at $t_{5}$, we can suppose that when $t_{1}$ is the objective present, if Fred can travel back from $t_{5}$ then so too can Mary. Suppose both Fred and Mary travel back in time to $t_{1}$. Then when $t_{1}$ is the present, both Fred and Mary exist at $t_{1}$, and both are appropriately related to their person stages that exist at $t_{5}$ : both Fred and Mary are time travellers. Yet when $t_{5}$ is the present, Fred exists at $t_{5}$, but since Mary's branch has dropped off, she does not exist at $t_{5}$. So when $t_{5}$ is the present, there exists no Mary person-stage at $t_{5}$ to cause the Mary stage at $t_{1}$.

If we think that when you remove the cause you remove the effect, then we will conclude that Mary exists at $t_{1}$ when $t_{1}$ is the present since the cause exists at $t_{5}$ - but does not exist at $t_{1}$ when $t_{5}$ is the present - since the cause does not exist at $t_{5}$. Then contra assumption (2), the past has been changed. Or one could deny the counterfactual component of an account of causation and maintain that it is tenselessly true that Mary exists at $t_{1}$. But then when $t_{5}$ is the present, Mary is not a genuine time traveller, since her $t_{1}$ person stage is not appropriately causally related to any person-stages in the future, and when $t_{1}$ is the present she is a genuine time traveller since the causal 
relations are present. This too violates (2) if we think that causal relations are in part intrinsic, since Mary changes from being a genuine time traveller to failing to be a time traveller.

So it seems that if presentism, the branching universe model and the growing universe model are the only ways that (5) can be true, we have shown that (1)-(5) are incompatible. Then given the plausibility of (1)(3), we should conclude that it is either (4) or (5) that is false. ${ }^{3}$ There are those who will be happy to reject (4). Those of us who do not find time travel paradoxical, however (Cf Lewis (1976); Horwich (1975); Sider (2002)), must reject (5). How startling this conclusion is depends in part on whether one thinks that if our world is a presentist, growing or branching universe, then it is necessarily so. This is a plausible contention: such models are probably not intended to be merely contingent, but rather, to capture something necessary about the nature of the present and the future. Of course, a rejection of (5) only entails that open future models are not necessarily true. However, those who accept the conditional that such models are either necessarily true or necessarily false, must conclude that if (5) is false, then it is necessarily false. Such persons who accept (4) will then conclude that open future models are necessarily false, a startling result.

Those who reject (5) by conceding that such models are merely contingent, can maintain that what is logically impossible is that there exists any world $\mathrm{W}$ that is an open future universe and in which time travel is possible. The problem is determining what sort of possibility we have in mind here. Not logical impossibility. Yet nomological impossibility does not quite seem to capture it either, since it is not merely the case that in open future universes it is not physically possible that there be time travel, rather, we want to say that time travel is somehow conceptually inconsistent with the open future. We want to say something like, if our world is an open future universe, then for the restricted set of worlds that are metaphysically like ours,

\footnotetext{
${ }^{3}$ Of course, one might reject (1) if one held that there are no real causal relations in the world, and thus that objects persist despite their stages not being causally related. Time travellers would then be no exception. If time travel required no causal relations, then no problem would ensue. Clearly this would be a good move only if one had independent grounds for thinking that there is no real causation, and presumably most of us do not, including Tooley and McCall.
} 
time travel in those worlds is impossible, and perhaps this is to say that if our world is an open future world, then time travel is metaphysically impossible.

\author{
Kristie Miller \\ Department of Philosophy \\ University of Queensland \\ Brisbane, Queensland, 4072, Australia \\ kristie_miller@yahoo.com
}

\title{
References
}

Braddon-Mitchell, D. 2004. How do I Know it is Now Now? Analysis 64(3) 199-203.

Dowe, P. 2000. The Case for Time Travel. Philosophy 75(293) 441-451.

Forrest, P. forthcoming. With Every Purchase of a Complete Set of TruthMakers you get Absolutely Free an Account of Physical Necessity. But Wait - There's More.

Goddu, G .C. 2003. Time Travel and Changing the Past: (or How to Kill Yourself and Live to Tell the Tale). Ratio 16(1)16-32.

Grey, W. 1999. Troubles with Time Travel. Philosophy 74: 55-70.

Horwich, P. 1975. On Some Alleged Paradoxes of Time Travel. Journal of Philosophy 72: 432-444.

Lewis, D. 1976. The Paradoxes of Time Travel. American Philosophical Quarterly 13: $145-152$.

McCall, S. 1994. A Model of the Universe: Space-Time, Probability, and Decision. Oxford: Clarendon Press.

Sider, T. 2002. Time Travel, Coincidences and Counterfactuals. Philosophical Studies 110:115-138.

Tooley, M. 1997. Time, Tense and Causation, Oxford: Clarendon Press. 